\title{
The effect of gender on survival for hemodialysis patients: why don't women live longer than men?
}

Surachet Vongsanim ${ }^{1}$, Andrew Davenport ${ }^{2}$

${ }^{1}$ Surachet Vongsanim surachet.vongsanim@nhs.net

Renal Division

Department of Internal Medicine

Faculty of Medicine

Chiang Mai University

110 Intrawarorot Road, Amphoe Mueang Chiang Mai

Chiang Mai 50200

Thailand

Tel +66 53930300

${ }^{2}$ Andrew Davenport andrewdavenport@nhs.net orchid 0000-0002-4467-6833

UCL Department of Nephrology, Royal Free Hospital, University College London,

Rowland Hill Street, London NW3 2PF

Tel +44-2074726457

Fax +44-2073178591

Correspondence

Professor Andrew Davenport andrewdavenport@nhs.net

UCL Centre for Dialysis \& Physiology, Department of Nephrology, Royal Free Hospital, University College London

Rowland Hill Street, London NW3 2PF

Tel +44-2074726457

Fax +44-2073178591

$\begin{array}{ll}\text { Abstract } & 290 \\ \text { Body } & 2692 \\ \text { Figures } & 4 \\ \text { Tables } & 3 \\ \text { References } & 38\end{array}$


Funding - nil

Acknowledgements - Dr Vongsanim was awarded an International Society of Nephrology training scholarship by the International Society of Nephrology and Kidney Research UK.

\begin{abstract}
Women in the general population have a survival advantage over men, but this advantage is not sustained in end-stage kidney disease (ESKD) patients treated by hemodialysis.

To understand why gender may affect survival we need to understand confounders which may affect dialysis practices. The current paradigm is to prescribe hemodialysis to achieve a target dialyzer urea clearance adjusted to total body water volume $\left(\mathrm{Kt} / \mathrm{V}_{\text {urea }}\right)$. Estimated glomerular filtration calculated from serum creatinine is often used to determine when patients start dialysis; as creatinine generation rates are lower in women, this may potentially result in a lead time bias with male patients starting dialysis earlier than females.

When hemodialysis dose is scaled to total body water $\left(\mathrm{Kt} / \mathrm{V}_{\text {urea }}\right)$ women receive shorter dialysis session times. Scaling dialysis for body surface area may be more appropriate since urea generation (a surrogate for uremic toxin production) depends upon resting energy expenditure (ie cellular metabolism) which reflects internal organ sizes. Resting energy expenditure is proportionally greater for smaller people. Women are generally smaller than men and as such have smaller sized internal organs. However, when comparing individuals, then internal organ size is best adjusted for using body surface area, not body water. The shorter, resultant dialysis session also results in lower middle molecule clearances, increases fluid removal rates and the risk of intra-dialytic hypotension; the latter potentially results in earlier loss of residual renal function.
\end{abstract}

Observational studies report that the association between survival and dialyzer $\mathrm{Kt} / \mathrm{V}_{\text {urea }}$ is improved after adjustment for body surface area, or energy expenditure. These studies also demonstrated that the conventional prescription of hemodialysis based on current $\mathrm{Kt} / \mathrm{V}_{\text {urea }}$ targets leads to less treatment delivered to women. These multiple consequences of the generally smaller size of women compared with men may account for the unexpectedly higher relative mortality for women. As such, prospective studies investigating alternative scaling parameters are required to confirm that increasing dialysis treatments for women improves survival. 


\section{Introduction}

In the majority of developed countries, women have greater survival compared to men in the general population across all age groups. Although other factors may be important, it seems likely that it is based on the distinct differences in physiology and body composition between the genders. However, this survival benefit for women has not been maintained in the ESKD population especially for hemodialysis patients. ${ }^{(1-3)}$ A study of 206,374 hemodialysis patients participating in the international Dialysis Outcomes and Practice Pattern Study (DOPPS) showed similar mortality rates between both genders in the hemodialysis population, significantly differing from a higher male-to-female mortality ratio reported in the Human Mortality Database (Figure 1). In some countries, such as France and Japan, the mortality of adult men was two-fold or greater compared to that for women in the general population, whereas in their respective hemodialysis populations, the survival advantage for women was markedly diminished. Data from European countries suggested that female hemodialysis patients had a greater risk of infectionrelated mortality compared to male patients. ${ }^{(4)}$ These findings are not just limited to adults, but also apply to children receiving dialysis treatment. A recent study reported that the mortality rate was $28 \%$ higher in girls compared to boys. ${ }^{(5)}$

The question arises as to why in the general population being female carries a survival advantage, whereas this gender advantage is lost in the ESKD hemodialysis population, and indeed survival may even be worse for women treated with hemodialysis.

\section{Potential confounders}

\section{Lead-time bias}

Mortality in dialysis patients is calculated from the time that patients start dialysis, although this starting time may vary between registries, with some registries calculating from the first dialysis treatment and others after 90 days or 3 months of dialysis, so as to exclude patients with acute kidney injury.

Residual renal function is now recognized as a major survival factor for dialysis patients. Thus, if patients start dialysis with greater residual renal function then this may offer a survival advantage, due to lead time bias.

The observational DOPPS phase 4 study reported that the average estimated glomerular filtration rate (eGFR) calculated by the Modification of 
Diet in Renal Disease Study (MDRD) formula was $10.6 \mathrm{ml} / \mathrm{min} / 1.73 \mathrm{~m}^{2}$ for male patients starting dialysis and $10.1 \mathrm{ml} / \mathrm{min} / 1.73 \mathrm{~m}^{2}$ for female patients. Although this would suggest that there was no major lead-time bias for male patients, dialysis was initiated at a lower eGFR in women in their ESRD course.$^{(3)}$ However, a closer look at the relationship between serum creatinine (the main determinant of eGFR) and actual GFR in the pre-dialysis population is warranted. Taking as an example, a 60-year-old non-African American male and female starting dialysis at these eGFRs $\left(10.6\right.$ and $10.1 \mathrm{ml} / \mathrm{min} / 1.73 \mathrm{~m}^{2}$, the serum creatinine values would be 5.83 and $4.69 \mathrm{mg} / \mathrm{dL}$ ( 515 and 415 $\mu \mathrm{mol} / \mathrm{L}$ ),respectively, for these patients..

Serum creatinine has long been used to estimate renal function before initiating the renal replacement therapy. Creatinine is a breakdown product of muscle metabolism and so depends upon muscle mass and physical activity. Women are likely to have lower muscle mass, lower dietary protein intake and be less physically active compared to aged-matched men. ${ }^{(6)}$ Moreover, postmenopausal women experience a greater decrease in lean mass, muscle fiber size, and muscle strength with age. ${ }^{(7)}$ A higher proportion of women start dialysis with moderate to severe muscle atrophy, a finding associated with greater mortality. ${ }^{(8)}$

The formulae currently used for estimating renal function from serum creatinine were developed from a variety of participants ranging from healthy individuals or those with stable mild chronic kidney disease down to those with a measured creatinine clearance of $7.5 \mathrm{~mL} / \mathrm{min} .{ }^{(9,10)}$ These equations may overestimate GFR in older patients with multiple comorbidities. Thus, for the same apparent eGFR value prior to initiating dialysis, serum creatinine was approximately $1.13 \mathrm{mg} / \mathrm{dL}(100 \mu \mathrm{mol} / \mathrm{L})$ lower in women than men. As such, using serum creatinine and eGFR to decide upon when patients should start dialysis may potentially result in a lead time bias, with male patients starting dialysis earlier than females.

\section{Loss of residual renal function}

Observational studies have highlighted that survival for both peritoneal and hemodialysis patients is greater for those with preserved renal function. ${ }^{(11}$,

12) The majority of patients initiating dialysis have some residual renal function. If women were more likely to be anuric at the initiation of dialysis, this would help explain the gender related dialysis mortality paradox. Many years ago, more female patients would start dialysis anuric from cortical necrosis following catastrophic post-partum hemorrhage, ${ }^{(13)}$ but with modern medicine this is now very rare. Other causes of anuria include hemolytic uremic syndrome which has a higher incidence in females ${ }^{(14)}$ but the frequency of such disorders is unlikely to substantially impact on survival.

It is now recognized that during a hemodialysis session, the blood flow to the kidney falls. This reduction in blood supply could increase the risk of acute 
ischemic damage and accelerate the loss of residual renal function in the hemodialysis patient. Registry reports and other observational studies have observed that women are more likely to suffer with intra-dialytic hypotension compared to men and thus, perhaps, a faster decline in residual renal function. However there are no studies specifically reporting on differences between genders and loss of residual renal function in patients initiating hemodialysis $(15,16$,$) .$

\section{Do women receive the same amount of dialyzer clearance?}

The National Co-operative Study (NCDS) investigated the effect of urea clearance hemodialysis patient outcomes. Gotch and Sargent then used the data for this landmark study to introduce a patient's urea clearance adjusted for urea volume $\left(\mathrm{Kt} / \mathrm{V}_{\text {urea }}\right)$ as a treatment target applicable to all patients. ${ }^{(17)}$ In the later National Institutes of Health-sponsored Hemodialysis (HEMO) study, the primary results demonstrated no significant overall effect for a higher dialyzer urea clearance on survival outcomes. However, in a prespecified subgroup analysis, women randomly assigned to the higher urea clearance target had a $19 \%$ lower mortality risk than women assigned to the standard urea clearance, whereas there was no difference in survival for male patients between the two clearance targets. ${ }^{(18)}$ Women assigned to the higher urea clearance target had fewer deaths caused by cardiac diseases, cerebrovascular diseases and vascular access complications.

This survival benefit in women of a higher urea clearance is supported by observational data from Japan. The Japanese DOPPS study cohort of 5,784 hemodialysis patients reported that the association between lower urea clearance and increased mortality was statistically much stronger for women than men. ${ }^{(19)}$ In addition, data from DOPPS and the United States also observed a significant reduction in mortality for women receiving greater urea clearance compared to the standard target clearance. Female dialysis patients with a urea reduction ratio (URR) of more than $75 \%$ had a $15 \%$ lower mortality risk compared to those with a URR of $70-75 \%$. As their equilibrated $\mathrm{Kt} / \mathrm{V}_{\text {urea }}$ $\left(\mathrm{eKt} / \mathrm{V}_{\text {urea }}\right)$ increased above 1.05 , mortality in women fell significantly. ${ }^{(20)}$ These positive correlations between increased urea clearance and patient survival in women were not observed in male dialysis patients suggesting that once male patients achieved the standard $\mathrm{Kt} / \mathrm{V}_{\text {urea }}$ target more urea clearance had no additional benefit. This would suggest that the standard $\mathrm{Kt} / \mathrm{V}_{\text {urea }}$ target has been set too low for women.

The basis behind the dimensionless $\mathrm{Kt} / \mathrm{V}_{\text {urea }}$ was that a single target threshold would apply to all patients. Patients' urea clearances are adjusted for their total body water (V). The V formulae in Watson's study were based on data from 30 different anthropometric studies selected to be representative of a healthy Western population. The relevance of these formulae to an aged, highly comorbid hemodialysis population in which malnutrition is prevalent is perhaps 
questionable. For any given age, height, and weight, the calculated $\mathrm{V}$ is lower in women than in men. For example, consider two 65-year-old hemodialysis patients of the opposite sex who both have same body weight of $80 \mathrm{~kg}$ and height of $175 \mathrm{~cm}$. Using Watson's formulae for V:

$$
\begin{aligned}
& \mathrm{V}_{\text {men }}=2.447-(0.09516 * \text { Age })+(0.1074 * \text { Height })+(0.3362 * \text { weight }) \\
& \mathrm{V}_{\text {women }}=-2.097+(0.1069 * \text { Height })+(0.2466 * \text { weight })
\end{aligned}
$$

Using these equations, the estimated $\mathrm{V}$ for a male patient is $42.2 \mathrm{~L}$ compared with $36.3 \mathrm{~L}$ for a female patient. These gender differences are due to an increased adipose tissue-to-fat free mass ratio in women, who have a disproportionately lower $\mathrm{V}$ for their body surface area. ${ }^{(21)}$ Thus, the man in this example would dialyze for $16.1 \%$ longer time than the woman to achieve the same Kt/V. ${ }^{(22)}$ However, as will be explained later, the use of $\mathrm{V}$, whether calculated or measured, to normalize dialysis dose $(\mathrm{Kt})$, is problematic.

The issue of body fat's influence on dialysis dose applies to both genders. Increasing body weight increases BMI; in dialysis patients it is most often that the ratio of fat to fat free weight increases, which leads to an over estimation of total body water (V) since adipose tissue contains less water than muscle. Thus, obese patients are prescribed longer dialysis sessions than are warranted based on their true $\mathrm{V}$ to achieve the same target single pool $\mathrm{Kt} /$ Vurea as smaller patients. ${ }^{(23)}$

Volume calculated with the variable-volume single-pool (VVSP) model is reported to be accurate in the range of $\mathrm{spKt} / \mathrm{V} 1.0$ to 1.2 , but then $\mathrm{V}$ is progressively overestimated as the $\mathrm{spKt} / \mathrm{V}$ increases above 1.2. ${ }^{(24)} \mathrm{As}$ a result, it is very likely that $\mathrm{spKt} / \mathrm{V}$ values $>1.2$ underestimate the true delivered dose for women. This has stimulated a search for alternative scaling parameters to allow equivalent dialysis treatment for women.

Resting energy expenditure (REE) closely correlates with fat free mass or body cell mass. Thus, it would be expected that REE is generally greater for men compared to women. At rest the highest metabolic activity is found in the internal organ compartment $(225.9 \mathrm{~kJ} / \mathrm{kg})$ which is much greater than that of resting skeletal muscle $(54.5 \mathrm{~kJ} / \mathrm{kg})$. This internal organ compartment has been termed the "high metabolic rate compartment" (HMRC). Only absolute HMRC mass significantly predicts protein catabolic rate. Consequently, it is likely that most uremic toxins are generated by metabolism in the liver, heart, brain, gut, and other internal organs, which together constitute the HRMC. The size of these internal organs do not increase or decrease proportionately with patient weight.

Therefore, the relative proportion of the HRMC for a small individual is increased compared to that of a larger person. (Table 1) Using data from retrospective studies, the approximate difference in internal organ size between men and women is only $10 \%$ despite a nearly $30 \%$ difference in their total body 
water calculated by Watson's formulae. ${ }^{(25-27)}$ Thus, adjusting for body size, then REE is relatively increased for (smaller) women compared to (larger) men, so indicating that women produce relatively more uremic toxins for their body size and so need a relatively greater urea clearance. ${ }^{(28-30)}$

Body surface area (BSA) correlates better with HRMC than weight, body water or body mass index (BMI), and as such it has been argued that urea clearance should be adjusted for BSA. Others have proposed total energy expenditure (TEE) a composite of REE and physical activity, which is linked to muscle mass. Analysis of patients' characteristics before randomization in the HEMO study showed that as V calculated from the Watson formulae decreased, the corresponding BSA calculated from the Dubois formula proportionally increased. Women had higher BSA to V ratio implying that for the same total body water, women had higher body surface area. ${ }^{(30)}$ Similar results have been observed our own dialysis program at the Royal Free Hospital (Figure 2).

Consequently, re-analysis of the HEMO study data showed that women had a higher single pool Kt/ $\mathrm{V}_{\text {urea }}$ compared to men, but when rescaled by BSA, then standard $\mathrm{Kt} / \mathrm{V}_{\text {urea }}$ was lower for women, and those women randomly assigned to the higher single pool $\mathrm{Kt} / \mathrm{V}_{\text {urea }}$ target received about the same BSAnormalized dose as men randomly assigned to standard single pool Kt $/ \mathrm{V}_{\text {urea }}$ target. ${ }^{(32,33)}$ Even though mean URR, spKt $/ \mathrm{V}_{\text {urea }}$, eKt $/ \mathrm{V}_{\text {urea }}$ and standard $\mathrm{Kt} / \mathrm{V}_{\text {urea }}$ $\left(\operatorname{stdKt} / \mathrm{V}_{\text {urea }}\right)$ were all greater in women than in men, dialysis dose normalized by surface area was lower in women than men. For $\mathrm{spKt} / \mathrm{V}_{\text {urea }}$, the adjusted mortality hazard ratio for both men and women decreased as $\mathrm{spKt} / \mathrm{V}_{\text {urea }}$ increased until a plateau at 1.6-1.7 was reached. Meanwhile, using surface-area normalized stdKt $/ \mathrm{V}_{\text {urea }}\left(\mathrm{SAN}-\mathrm{stdKt} / \mathrm{V}_{\text {urea }}\right)$ mortality risk progressively decreased as $\mathrm{SAN}-$ stdKt $/ \mathrm{V}_{\text {urea }}$ increased. ${ }^{(33)}$ Using a surface-area normalized measure is physiologically appealing as renal glomerular filtration rate in the normal population is scaled to body surface area rather than $\mathrm{V}$.

It might be expected that patients with a higher metabolic rate would require more dialyzer clearance than those with a lower rate, as increased energy expenditure is associated with higher level of urea generation in hemodialysis patients. Women usually have a smaller body size compared to men but a relatively higher proportion of HMRC. Therefore, scaling dialysis dose to $\mathrm{V}$ may lead to less dialysis in women. Recent retrospective analysis of a cohort of 1,500 hemodialysis patients in the UK reported greater 2-year survival outcomes in patients who received urea clearances exceeding both conventional target spKt/ $\mathrm{V}_{\text {urea }}$ and adjusted targets based on the Kt/TEE and Kt/BSA (Table

2) compared to those who achieved only conventional $s p K t / \mathrm{V}_{\text {urea }}$ targets. ${ }^{(6)}$

These observational studies generate hypotheses, ${ }^{(34)}$ which would need to be tested in large prospective studies comparing the dialyzer urea clearance scaled to BSA or TEE.

\section{Do women have shorter dialysis sessions?}


Another consequence of the generally smaller size of women is that the associated smaller $\mathrm{V}$ means that a lower Kt will be required to achieve a target $\mathrm{Kt} / \mathrm{V}$. This usually means that a woman will receive a shorter treatment than a man. To compare the effect of using $\mathrm{Kt} / \mathrm{V}_{\text {urea }}$ in current practice, we created hemodialysis patient characteristics of both genders achieving the same dialysis dose (Table 3). The formula calculating single-pooled $\mathrm{Kt} / \mathrm{V}(\mathrm{spKt} / \mathrm{V})$ was as following.

$$
\mathrm{spKt} / \mathrm{V}=-\ln (\mathrm{R}-0.008 * \mathrm{t})+(4-3.5 * \mathrm{R}) * \mathrm{UF} / \mathrm{W}
$$

where: $\mathrm{R}$ is the post/pre-plasma urea nitrogen ratio,

$t$ is dialysis session duration (in hours),

UF is the ultrafiltrate volume (in liters),

$\mathrm{W}$ is post-dialysis body weight (in kilograms)

In this hypothetical example, it is easier to achieve the same target $\mathrm{spKt} / \mathrm{V}_{\text {urea }}$ in the smaller women compared to the heavier man, with shorter dialysis sessions and ultrafiltration volume. This is in keeping with previous studies, as to achieve targeted dialysis dose normalized by $\mathrm{V}$, women required less dialysis treatment time compared to men (Figure $3 a, 3 b){ }^{(3,6,18,19)}$

A shorter duration of dialysis may deliver similar urea clearance, but this does not mean that both patients receive same dialysis treatment. Urea kinetics differ significantly from the kinetic behavior of other metabolites that accumulate in patients with end stage kidney disease, including phosphate, middle molecules and protein bound solutes. ${ }^{(36)}$ Compared with urea, many other solutes, such as phosphate ${ }^{(37)}$ and middle molecules, ${ }^{(38)}$ show markedly increased removal when dialysis session time is prolonged. This is supported by a study from Belgium using a fixed volume of dialysate, which demonstrated that increasing the dialysis session time resulted in more uremic solute removal but with no difference in $\mathrm{Kt} / \mathrm{V}_{\text {urea.. }}{ }^{(39)}$

In addition to the effects on solute clearances, a shorter dialysis session time may have other consequences. There is an association between extracellular volume overload and mortality for hemodialysis patients. Shorter dialysis session times increase risks for failure to achieve sodium and volume homeostasis and excessive ultrafiltration rates, the latter leading to intra-dialytic hypotension and premature loss of residual renal function which both have their own ill effects on outcomes.

Thus, when equivalent $\mathrm{Kt} / \mathrm{V}$ values are achieved with differing treatment times $(\mathrm{t})$, erroneous conclusions can be reached regarding the actual equivalency of treatments. (This error will apply regardless of whether alternatives to $\mathrm{V}$ are used to dose therapy, especially as dialysis treatment is much more than a target urea removal). The smaller $\mathrm{V}$ and consequent smaller $\mathrm{t}$ 
required in women may be another factor explaining the unexpected absence of a lower mortality rate in women on dialysis.

\section{Conclusion}

The current hemodialysis paradigm to target a universal dialyzer urea clearance threshold may well be satisfactory for larger male patients, but appears to provide female patients with a lower effective dialysis dose. Recognition of this problem is the first step to develop a better standard of care for our female patients. While developing innovative dialysis strategies and improving machines technology are important to advance dialysis treatment, we also need to explore alternative ways to measure dialysis dose and develop new target thresholds for treatment particularly for women. That the survival advantage for women in the general population is absent in those on dialysis indicates a flaw in our current dialysis treatment paradigm. It should be considered more than an interesting observation.

Neither author has any conflicts of interest.

\section{Reference}

1. Centers for Disease Control and Prevention, National Center for Health Statistics. Compressed Mortality File 1999-2016 on CDC WONDER Online Database, released June 2017. Data are from data provided by the 57 vital statistics jurisdictions through the Vital Statistics Cooperative Program. Accessed February 21, 2019. Available from: http://wonder.cdc.gov/cmficd10.html.

2. United States Renal Data System: The 2018 Annual Data Report 2018 [cited $201918 \mathrm{Feb}$ ]. Available from: www.usrds.org/2018/view/default.aspx. 3. Hecking M, Bieber BA, Ethier J, et al. Sex-specific differences in hemodialysis prevalence and practices and the male-to-female mortality rate: the Dialysis Outcomes and Practice Patterns Study (DOPPS). PLoS Med. 2014;11(10):e1001750.

4. Vogelzang JL, van Stralen KJ, Noordzij M, et al. Mortality from infections and malignancies in patients treated with renal replacement therapy: data from the ERA-EDTA registry. Nephrol Dial Transplant. 2015;30(6):102837.

5. Ahearn P, Johansen KL, McCulloch CE, et al. Sex Disparities in Risk of Mortality Among Children With ESRD. Am J Kidney Dis. 2019;73(2):156-62. 6. Sridharan S, Vilar E, Davenport A, et al. Indexing dialysis dose for gender, body size and physical activity: Impact on survival. PLoS One. 2018;13(9):e0203075. 
7. Carson JA, Manolagas SC. Effects of sex steroids on bones and muscles: Similarities, parallels, and putative interactions in health and disease. Bone. 2015;80:67-78.

8. Carrero JJ, Chmielewski M, Axelsson J, et al. Muscle atrophy, inflammation and clinical outcome in incident and prevalent dialysis patients. Clin Nutr. 2008;27(4):557-64.

9. Levey AS, Coresh J, Greene T, et al. Using standardized serum creatinine values in the modification of diet in renal disease study equation for estimating glomerular filtration rate. Ann Intern Med. 2006;145(4):247-54.

10. Levey AS, Stevens LA, Schmid CH, et al. A new equation to estimate glomerular filtration rate. Ann Intern Med. 2009;150(9):604-12.

11. Shafi T, Jaar BG, Plantinga LC, et al. Association of residual urine output with mortality, quality of life, and inflammation in incident hemodialysis patients: the Choices for Healthy Outcomes in Caring for End-Stage Renal Disease (CHOICE) Study. Am J Kidney Dis. 2010;56(2):348-58.

12. van der Wal WM, Noordzij M, Dekker FW, et al. Full loss of residual renal function causes higher mortality in dialysis patients; findings from a marginal structural model. Nephrol Dial Transplant. 2011;26(9):2978-83. 13. Naqvi R, Akhtar F, Ahmed E, et al. Acute renal failure of obstetrical origin during 1994 at one center. Ren Fail. 1996;18(4):681-3.

14. Terrell DR, Vesely SK, Kremer Hovinga JA, et al. Different disparities of gender and race among the thrombotic thrombocytopenic purpura and hemolytic-uremic syndromes. Am J Hematol. 2010;85(11):844-7.

15. Sands JJ, Usvyat LA, Sullivan T, et al. Intradialytic hypotension: frequency, sources of variation and correlation with clinical outcome. Hemodial Int. 2014;18(2):415-22.

16. Flythe JE, Xue H, Lynch KE, et al. Association of mortality risk with various definitions of intradialytic hypotension. J Am Soc Nephrol. 2015;26(3):724-34.

17. Gotch FA, Sargent JA. A mechanistic analysis of the National Cooperative Dialysis Study (NCDS). Kidney Int. 1985;28(3):526-34.

18. Depner T, Daugirdas J, Greene T, et al. Dialysis dose and the effect of gender and body size on outcome in the HEMO Study. Kidney Int. 2004;65(4):1386-94.

19. Kimata N, Karaboyas A, Bieber BA, et al. Gender, low Kt/V, and mortality in Japanese hemodialysis patients: opportunities for improvement through modifiable practices. Hemodial Int. 2014;18(3):596-606.

20. Port FK, Wolfe RA, Hulbert-Shearon TE, et al. High dialysis dose is associated with lower mortality among women but not among men. Am J Kidney Dis. 2004;43(6):1014-23.

21. Watson PE, Watson ID, Batt RD. Total body water volumes for adult males and females estimated from simple anthropometric measurements. Am J Clin Nutr. 1980;33(1):27-39. 
22. Wolfe RA, Ashby VB, Daugirdas JT, et al. Body size, dose of hemodialysis, and mortality. Am J Kidney Dis. 2000;35(1):80-8.

23. Davenport A. Differences in prescribed $\mathrm{Kt} / \mathrm{V}$ and delivered hemodialysis dose--why obesity makes a difference to survival for hemodialysis patients when using a 'one size fits all' Kt/V target. Nephrol Dial Transplant. 2013;28 Suppl 4:iv219-23

24. Gotch FA, Sargent JA, Keen ML. Whither goest Kt/V? Kidney Int Suppl. 2000;76:S3-18.

25. Chouker A, Martignoni A, Dugas M, et al. Estimation of liver size for liver transplantation: the impact of age and gender. Liver Transpl. 2004;10(5):678-85.

26. Ho KC, Roessmann U, Straumfjord JV, et al. Analysis of brain weight. II. Adult brain weight in relation to body height, weight, and surface area. Arch Pathol Lab Med. 1980;104(12):640-5.

27. Yang CC, Chen TC, Wu CS, et al. Sex differences in kidney size and clinical features of patients with uremia. Gend Med. 2010;7(5):451-7.

28. Sarkar SR, Kuhlmann MK, Kotanko P, et al. Metabolic consequences of body size and body composition in hemodialysis patients. Kidney Int. 2006;70(10):1832-9

29. Hung R, Sridharan S, Farrington K, et al. Comparison of estimates of resting energy expenditure equations in hemodialysis patients. Int J Artif Organs. 2017;40(3):96-101.

30. Oliveira B, Sridharan S, Farrington K, et al. Comparison of resting energy equations and total energy expenditure in hemodialysis patients and body composition measured by multi-frequency bioimpedance. Nephrology (Carlton). 2017 Jul 13. doi: 10.1111/nep.13112. PMID: 28703894

31. Daugirdas JT, Levin NW, Kotanko P, et al. Comparison of proposed alternative methods for rescaling dialysis dose: resting energy expenditure, high metabolic rate organ mass, liver size, and body surface area. Semin Dial. 2008;21(5):377-84.

32. Daugirdas JT, Greene T, Chertow GM, et al. Can rescaling dose of dialysis to body surface area in the HEMO study explain the different responses to dose in women versus men? Clin J Am Soc Nephrol. 2010;5(9):1628-36.

33. Ramirez SP, Kapke A, Port FK, et al. Dialysis dose scaled to body surface area and size-adjusted, sex-specific patient mortality. Clin J Am Soc Nephrol. 2012;7(12):1977-87.

34. Spalding EM, Chandna SM, Davenport A, et al. Kt/V underestimates the hemodialysis dose in women and small men. Kidney Int. 2008;74(3):348-55 35. Sridharan S, Vilar E, Davenport A, et al Scaling Hemodialysis Target Dose to Reflect Body Surface Area, Metabolic Activity, and Protein Catabolic Rate: A Prospective, Cross-sectional Study. Am J Kidney Dis. 2017;69(3):358366. 
36. Eloot $\mathrm{S}$, Torremans A, De Smet R, et al. Kinetic behavior of urea is different from that of other water-soluble compounds: the case of the guanidino compounds. Kidney Int. 2005;67(4):1566-75.

37. Ratanarat R, Brendolan A, Volker G, et al. Phosphate kinetics during different dialysis modalities. Blood Purif. 2005;23(1):83-90.

38. Goldfarb-Rumyantzev AS, Cheung AK, Leypoldt JK. Computer simulation of small-solute and middle-molecule removal during short daily and long thrice-weekly hemodialysis. Am J Kidney Dis. 2002;40(6):1211-8.

39. Eloot S, Van Biesen W, Dhondt A, et al. Impact of hemodialysis duration on the removal of uremic retention solutes. Kidney Int. 2008;73(6):765-70. Leypoldt JK, Weinhandl DE, Collins AJ. Volume of urea cleared as a therapy dosing guide for more frequent dialysis. Hemodial Int. 2019;23(1):42-49

Figure 1 Male-to-female mortality ratio between general population and hemodialysis population in DOPPS countries.

Figure 2 Association between ratio of body surface area to Watson V (BSA/V) and Watson V in both genders. Patient sample from Royal Free Hospital data; 730 male, 410 female hemodialysis patients.

Figure 3 (a) Urea reduction ratio (b) Hemodialysis session time difference between both genders. Patient sample from Royal Free Hospital data; 690 male, 438 female hemodialysis patients.

Table 1 Estimation of internal organs size between both genders from patients of Royal Free Hospital

\begin{tabular}{|l|c|c|c|}
\hline Parameters & Male & Female & \% Difference \\
\hline Weight, $\mathrm{kg}$ & 75 & 65 & 15.4 \\
\hline $\mathrm{V}_{\text {Watson }} \mathrm{L}$ & 41.9 & 32.6 & 28.3 \\
\hline BSA, $\mathrm{m}^{2}$ & 1.87 & 1.72 & 8.7 \\
\hline Brain, $\mathrm{g}$ & 1,336 & 1,196 & 11.7 \\
\hline
\end{tabular}




\begin{tabular}{|l|c|c|c|}
\hline Liver, g & 2,270 & 2,104 & 7.9 \\
\hline $\begin{array}{l}\text { Kidney length, } \\
\text { cm }\end{array}$ & 10.3 & 9.5 & 8.4 \\
\hline
\end{tabular}

Table 2 Recommended minimum spKt/V target based on gender, body size and activity level adjustment

\begin{tabular}{lccc}
\hline & Sedentary & Light Active & Active \\
\hline Large males & 1.4 & 1.6 & 1.8 \\
Small males & 1.5 & 1.6 & 1.8 \\
Female & 1.7 & 1.7 & 1.8 \\
\hline
\end{tabular}

Table 3 Patient characteristics and dialysis parameters.

\begin{tabular}{|l|c|c|}
\hline Parameters & Male & Female \\
\hline Body weight, kg & 70 & 50 \\
\hline $\begin{array}{l}\text { Pre-dialysis BUN, mg/dL } \\
\text { (mmol/L) }\end{array}$ & $84.0(30.0)$ & $70.0(25.0)$ \\
\hline $\begin{array}{l}\text { Post-dialysis BUN, mg/dL } \\
\text { (mmol/L) }\end{array}$ & $25.2(9.0)$ & $21.0(7.5)$ \\
\hline Dialysis time, hours & 4 & 3 \\
\hline Ultrafiltration volume, L & 2 & 1.5 \\
\hline Urea reduction ratio & 70 & 70 \\
\hline spKt/V & 1.4 & 1.41 \\
\hline
\end{tabular}

